\title{
The Interaction of Syntax and Semantics in Countability and Number Marking
}

\author{
Eun-Joo Kwak \\ Sejong University, Korea
}

\begin{abstract}
Countability and number marking are basically specified by morpho-syntactic structures. However, they are closely related with the denotations of noun phrases. Hence, it needs to be scrutinized (i) whether syntax and semantics are interrelated to mark the relevant information, and (ii) in what way they are. In this study, we will review diverse linguistic data to analyze patters for countability and number marking. Finally, it will be concluded that syntax and semantics are deeply intertwined each other even in languages where countability and number are not explicitly marked or marked in the opposite ways of nominal denotations.
\end{abstract}

Keywords: countability, object, substance, number, plural

\footnotetext{
Eun-Joo Kwak

Department of English Language and Literature, Sejong University

98 Gunja-dong, Gwangjin-gu, Seoul 143-747, Korea

Email: ejkwak@sejong.ac.kr
} 
2 The Interaction of Syntax and Semantics in Countability and Number Marking

\section{Introduction}

What is meant by expressions and sentences appears deeply rooted with the state of the affairs in the real world. This close relation sometimes leads to the belief that meanings cannot be separated from the physics of the real world. When it comes to countability and plurality, this belief may be rephrased in a way that countable objects should be represented by count nouns and that more than one object should be put into plural noun phrases (henceforth NPs). This unilateral correlation, however, may not be sustained crosslinguistically. Substances, which cannot be counted, may be represented by count nouns and sometimes even by plural NPs. In contrary with this, countable objects may be represented by noncountable mass nouns. Mismatches between the countability of nouns and their interpretations induce the other extreme belief that countability and plurality are purely morpho-syntactic matters, having no relation to semantics at all.

The mixed beliefs regarding countability and plurality arouse the necessity to scrutinize how close syntax and semantics are interrelated and in what way they are. As part of efforts for the scrutiny, we will consider diverse patterns of countability and plurality cross-linguistically and then see how mismatched NPs between their syntax and semantics are construed. In spite of apparent mismatches, we will see how semantics is reflected to the syntax of NPs and what aspect of semantics is manifested in diverse languages. 


\section{Countability and Number Marking Affected by Animacy}

Countability may appear a simple notion such that physically countable objects are represented by count nouns while physically non-countable substances are denoted by mass nouns. ${ }^{1}$ At first glance, this simple notion seems to be tenable. Objects like apples are denoted by count nouns like apple, and substances like water by mass nouns like water. Distinction between count and mass nouns is noted in several ways. In English, only count nouns may be pluralized, and may be preceded by numeral expressions and count adjectives like small (cf. Quine 1960).

(1) a. apples

b. two apples

c. small apples

(2) a. *waters

b. *two water(s)

c. *small water

As seen in (1), apple, a count noun, has the plural form apples, and it may be preceded by the numeral two or the count adjective small. All these are not allowed to the substance noun water as in (2).

In addition to the morpho-syntactic tests as in (1) and (2), sentence interpretations, namely quantity comparatives, are also conducive to

1 Chierchia (2010) calls nouns for non-countable substances 'canonical mass nouns' and further specifies them in four groups depending on their meanings: nouns for fluid (e.g., water, beer), paste (e.g., dough, clay), mineral (e.g., gold), and assorted material (e.g., wood, bronze, sand). 
4 The Interaction of Syntax and Semantics in Countability and Number Marking

countability distinction. According to Barner \& Snedeker (2005) and Bale \& Barner (2009), what is compared is different depending on nominal denotations. Objects denoted by count nouns induce comparative readings as to number while substances denoted by mass nouns arouse comparative readings as to volume.
(3) a. A has more apples than B.
[assessed on numerosity]
b. A has more water than B.
[assessed on volume]

More apples in (3a) means that the number of apples that $\mathrm{A}$ has is more than that of $\mathrm{B}$. The total size or volume of apples is not relevant here. On the other hand, more water in ( $3 b)$ means a larger volume of water. How many portions of water A has does not matter in (3b).

Although the distinction between objects and substances is strongly tenable in many languages, this simple dichotomy may not be sustained cross-linguistically. ${ }^{2}$ Smith-Stark (1974) and Corbett $(1996,2000)$ argue that nouns with high animacy have more chance to be count. According to an animacy scale suggested by them, human nouns are ranked in the highest position of the scale, and they are followed by nouns denoting larger animals, nouns denoting smaller animals, and finally inanimate objects. Positions in the animacy scale are related with countability. In other words, nouns

2 This dichotomy is not sustained even intra-linguistically. For instance, although the denotation of a group noun like footwear is based on objects, it shows mixed properties as to countability.

(i) a. *footwears

b. *two footwears

c. small footwear

Footwear behaves like water as to pluralization and the occurrence of a numeral while it may be preceded by a count adjective like apple. 
ranked higher in the animacy scale have more chances to be count nouns than those in lower positions.

According to theories involving the animacy scale, human nouns are most likely to be count nouns, which are attested by diverse cross-linguistic data. In Slave, an Athabaskan language spoken in British Columbia and Alberta, Canada, a plural suffix ke may occur optionally with nouns denoting humans and dogs but never with nouns denoting inanimate entities (cf. Rice 1989). In Manchu, a Tungusic language of northern China, pronouns and most human nouns are number-marked (cf. Corbett 2000). Even when number marking is done by verbs, the animacy scale is tenable. For example, only human nouns and nouns for higher animates like spirits are number-marked in verbs in Mayali, a Gunwinjguan language of western Arnhem Land, Australia (cf. Evans 1995).

Even in the case that plural marking is prevalent to apply to all lexical items in a language, the semantic feature of animacy may still be feasible. Deal $(2010,2016)$ provides interesting data of Nez Perce, a Sahaptian language spoken in Idaho, Washington, and Oregon, USA. In Nez Perce, which has a flexible word order, both object and substance nouns may combine with a numeral. For instance, the substance noun tuutnin 'flour' may combine with a numeral like lepit 'two', which induces a counting reading such as 'two piles of flour'. ${ }^{3}$ Since the reading of two piles of flour does not involve conventional package or units, it is not the case of a coerced reading or a shifted reading from mass to count. Other substance nouns consistently show that they may combine with a numeral freely, which shows that all nouns in Nez Perce are count nouns.

\footnotetext{
3 Another interpretation of lepit tuutnin 'two flour' is a subkind reading such as two kinds of flour. Since subkind readings are also considered as part of counting readings, I will not discuss subkind readings further in this paper.
} 
6 The Interaction of Syntax and Semantics in Countability and Number Marking

In addition to the co-occurrence of a numeral, count adjectives may occur with mass nouns in Nez Perce. In English, count adjectives such as small and big may not occur with substance nouns as exemplified in (2c) and (4).

(4) \#big water

(5) a. himeeq'is picpic big cat

'(the) big cat'

b. himeeq'is kuus big water '(the) big portion of water'

However, substance nouns in Nez Perce allow the co-occurrence of count adjectives. Kuus 'water' denotes the substance of liquid and is highly restricted to be delivered by a mass noun in diverse languages. However, this is not true in Nez Perce, which triggers a belief that all nouns in Nez Perce are equally count regardless of semantic features like animacy.

Given the morpho-syntactic evidence for countability, semantic factors do not seem to be incorporated in the countability of $\mathrm{Nez}$ Perce; all nouns appear to behave like count nouns regardless of semantic features. A more scrutiny, however, shows that distinction between objects and substances is still tenable in many ways. First, number marking is distinguished depending on nominal classes. Basically, plurality may be marked on nouns, verbs, adjectives in Nez Perce. Given the diverse ways of plural marking, human nouns are most actively marked, and thus nouns, verbs, and adjectives may all be plural-marked. In contrast, non-human animate nouns allow only verbal and adjectival plural marking, and inanimate nouns allow just adjectival plural marking. 
(6) The Distribution of Plural Marking in Nez Perce

\begin{tabular}{|l|lcc|}
\hline Animacy Class & Noun & Verb & Adjective \\
\hline Human & Y(mostly $)$ & Y & Y \\
\cline { 2 - 2 } $\begin{array}{l}\text { Non-human } \\
\text { Animate }\end{array}$ & $\mathrm{N}$ & $\mathrm{Y}$ & $\mathrm{Y}$ \\
Inanimate & $\mathrm{N}$ & $\mathrm{N}$ & $\mathrm{Y}$ \\
\hline
\end{tabular}

The distribution pattern in (6) shows that the semantic feature of animacy plays a crucial role in plural marking in Nez Perce. Human nouns, which take the highest position in the animacy scale, are widely plural-marked while inanimate nouns are passively pluralmarked just on adjectives.

Here are examples of nominal plural marking in Nez Perce:

(7) Humans

\begin{tabular}{lll} 
Gloss & Singular & Plural \\
\hline 'friend(s)' & lawtiwaa & lawtiwaa-ma \\
'woman/women' & 'aayat & ha-'aayat
\end{tabular}

(8)

\begin{tabular}{|c|c|c|c|}
\hline Non-hum & Animates & b. Inanimates & \\
\hline Gloss & Noun & Gloss & Noun \\
\hline 'cat(s)' & picpic & ' $\operatorname{rock}(\mathrm{s}) '$ & piswe \\
\hline 'horse(s) & sik'em & 'house(s)' & 'iniit \\
\hline
\end{tabular}

Human nouns for friend and woman have dual nominal forms, one for singular and the other for plural. However, non-human animate nouns for 'cat' and 'horse' and inanimate nouns for 'rock' and 'house' have only number-neutral forms which are not plurally marked. Similarly, when human nouns and non-human animates 
8 The Interaction of Syntax and Semantics in Countability and Number Marking

occur in a sentence, co-occurring verbs are distinguished in number as in (9a).

(9) a. lepit picpic hi-w-s-iix/*hii-we-s 'iniit-pe. two cat 3SUBJ-be-PRES-PL/*3SUBJ-be-PRES house-in 'Two cats are in the house.'

b. lepit cepeepy'uxtin' hii-w-s/*hii-we-s-iix 'iniit-pe. two pie 3SUBJ-be-PRES/*3SUBJ-be-PRES-PL house-in 'Two pies are in the house.'

However, inanimate nouns like cepeepy'uxtin' 'pie(s)' are not accompanied by a plural marking morpheme even when they are preceded by a numeral as in (9b). Contrasting with the restricted marking on nouns and verbs, adjectives are plurally marked for any class of nouns as exemplified in (10).
a. yox-me ki-kuhet ha-'aayat hi-w-s-iix
'emti.
DEM-PL PL-tall PL-woman 3SUBJ-be-PRES-PL outside 'Those tall women are outside.'
b. Himeeq'is 'itet'es-pe hii-we-s ki-kuckuc taam'am. big bag-in 3SUBJ-be-PRES PL-small egg 'In the big bag there are little eggs.'

The adjectives in (10a) and (10b) are preceded by the plural morpheme $k i$, occurring with the human noun ha-'aayat 'women' and the animate noun taam'am 'egg(s)', respectively. There is no difference in the plural marking of adjectives.

Another example which shows that number marking is highly affected by the semantic feature of animacy is given by Lima (2014). 
Lima provides interesting data on Yudja, a Tupí language spoken in Brazil, where all nouns including both object and substance nouns may combine with numerals. In (11), the numeral txabïu 'three' occurs with both the object noun $b a^{\prime} i$ ' 'paca' and the substance noun yukidï 'salt'.

(11) a. Txabïu ba'ï wãnã.

three paca ran

'Three pacas ran.'

b. Maria txabïu yukïdï apa.

Maria three salt drop

'Maria dropped three portions of salt.'

Considering the fact that the co-occurrence of numerals is one the main morpho-syntactic tests for countability, all nouns in Yudja appear to be count regardless of semantic features.

Although nouns are not distinct as to the numeral structure in Yudja, plural morphology is confined only to human nouns, being sensitive to the semantic feature of nouns. The plural suffix $-i$ may occur with the human noun senahï 'man' but not with the nonhuman noun kota 'snake' in (12).

(12) Senahï-i kota ixu.

man-PL snake eat

'(The) men eat/ate a/the/some snake(s).'

Again, the semantic feature of animacy affects the morpho-syntax of Yudja in spite of the apparent prevalent countability of nouns in terms of numeral structures. 
10 The Interaction of Syntax and Semantics in Countability and Number Marking

The semantic feature of animacy is useful not only in the distinction of countability but also in the decision of unmarked forms of nouns as to number. Many languages with a number marking system show patterns like English. Singular nouns are unmarked while plural nouns are morpho-syntactically marked. However, this is not always the case as exemplified by Dagaare, a Gur language spoken in Niger-Congo (cf. Grimm 2012). A specific morpheme -ri is adopted to mark number in Dagaare, but which noun is followed by $-r i$ is not changeable depending on the semantic properties of nouns. Nouns with high animacy are unmarked in the singular while nouns with low animacy are unmarked in the plural.

\begin{tabular}{llll} 
Gloss & Stem & Singular & Plural \\
\hline 'child' & bì- & bíé & bíírí \\
'seed' & bí- & bírì & bíê
\end{tabular}

The number-marking morpheme -ri occurs either the plural noun biirí 'children' or the singular noun birì 'seed'. This shows that the marked form in number is the singular noun bié for bì - 'child' while it is the plural noun biè for bí - 'seed'. ${ }^{4}$

Animacy also affects the naturalness of plural marking depending on languages. The distinction of object and substance is reflected in the countability of Korean. Objects are basically represented by count nouns and substances are by mass nouns. Plurality is overtly marked on nouns with the plural morpheme -tul. As shown in (14), object nouns regardless of humanness are count nouns and may be followed by the plural morpheme while substance nouns are not allowed to be plurally marked (cf. Kwak 2014).

${ }^{4}$ Different patterns of number marking as shown by Dagaare are called inverse number marking'. 


$\begin{array}{cl}\begin{array}{c}\text { (14) haksayng-tul } \\ \text { student-PL }\end{array} & \begin{array}{l}\text { [human] } \\ \text { 'students' }\end{array} \\ \begin{array}{c}\text { b. sakwa-tul } \\ \text { apple-PL }\end{array} & \begin{array}{l}\text { [non-human object] } \\ \text { 'apples' }\end{array} \\ \text { c. *mwul-tul } & \text { [substance] } \\ \text { water-PL } & \text { '\#waters' }\end{array}$

Unlike English, the plural morpheme -tul is optional in Korean, and thus plural NPs may not be accompanied by -tul in sentences. Furthermore, which NPs are explicitly marked for plurality is affected by the semantic feature of nouns. Nouns ranked low in the animacy scale are less likely to be plurally marked than nouns in the higher positions. Hence, the human noun in (14a) naturally occurs with the plural morpheme in a sentence as in (15a), and the substance noun in (14c) is not allowed to occur with the plural morpheme as shown in (15c). Interestingly, however, the legitimate plural-marked noun in (14b) is not understood quite natural in a sentence.

(15) a. Haksayng-tul-i pointa. student-PL-NOM are-seen 'Students are seen.'

b. ??Sakwa-tul-ul sassta. apple-PL-ACC bought '(pro) bought apples.'

c. *Mwul-tul-i ssotacyessta. water-PL-NOM was-poured 'Water was poured.' 
12 The Interaction of Syntax and Semantics in Countability and Number Marking

The different acceptability in (15) shows that the naturalness of plural NPs may vary depending on noun classes which are divided by the semantic feature of animacy.

\section{Interpretations of Substance Nouns}

\subsection{Languages with No Mass Nouns in Morpho-syntax}

Countability is attested by the several morpho-syntactic tests as discussed in the previous section. Moreover, the morpho-syntax of countability is highly associated with the semantic distinction between objects and substances in many languages. In spite of the close correlation between countability and objecthood of nouns, there are apparent exceptions to this general tendency. All nouns may appear to count or all nouns may appear to mass depending on languages. The lack of the countability distinction in these languages arouses a question whether object and substance nouns are assign equal interpretations. We will pursue this question with diverse linguistic data.

Nez Perce is a language in which all nouns may be plural-marked, specifically on their co-occurred adjectives. For instance, the object noun 'ileeptik'ey 'sock' and the substance noun qahas 'milk' may occur with the pluralized adjective $t i$ - $t a$ 'c 'PL-good' as in (16).

(16) a. 'Isii-nm 'uus qetu 'ilexni ti-ta'c/*ta'c 'ileeptik'ey? who-GEN have-PRES COMP a_lot PL-good/good sock 'Who has more good socks?' 
b. 'Isii-nm 'uus qetu 'ilexni ti-ta'c/ta'c qahas? who-GEN have-PRES COMP a_lot PL-good/good milk 'Who has more portions of/more good milk?'

The two categories of nouns seem to be identical in that the same plural-marked adjective may occur. However, the morpho-syntax related with these nouns is distinct in the way that the object noun 'ileeptik'ey 'sock' is not allowed to occur with the non-pluralized adjective when preceded by a quantifier like 'ilexni 'a lot'. Another difference is that the interpretation of the comparative sentence with the substance noun is diverged depending on the number marking of the adjective. Occurring with the non-plural adjective, the comparative NP in (16b) is construed as a more volume of milk. On the other hand, the plural-marked adjective induces the comparison of numerosity such as more portions of milk. This shows that even if dual forms of adjectives are allowed to the substance noun, they induce different readings. Occurring with the non-plural adjective, the substance noun behaves like an ordinary mass noun in its interpretation. Occurring with the plural adjective, the substance noun behaves like a count noun in its interpretation. This shows that object and substance nouns are distinguished both in their morphosyntax and semantics.

To derive the count reading of the mass noun as in (16b), Deal (2010, 2016) proposes that pluralized NPs and counting readings with substance nouns involve a silent or phonologically null operator $\alpha_{\mathrm{n}}$, which divides the mass of substance into portions of substance. Or its function may be described as mapping homogeneous denotations to quantized ones. For instance, when $\alpha_{n}$ applies to an NP with the substance noun for bread, it will give the set of loaves of 
14 The Interaction of Syntax and Semantics in Countability and Number Marking

bread, a quantized reading of bread. ${ }^{5}$

As is well known, derived count readings or shifted readings from mass to count are quite restricted in English and they are allowed only in restricted context where conventional portions or units are provided. However, count readings of substance are not subject to additional restrictions in Nez Perce. Hence, Deal argues that count readings of substance are not shifted readings from mass to count. Rather, they result from the application of the silent divider, which may apply to any substance noun.

Pluralized substance nouns are observed in more languages including French, Hebrew, Persian, and Biblical English (cf. Mathieu 2012). In all these languages, substance nouns may occur with nonplural adjectives, determiners, verbs, etc. However, plural-marked forms are also allowed.

(17) a. La fonte des neiges

[French]

the melting of.the snow-PL

'The melting of the snow'

b. Iarad

harbe šlagim.

[Hebrew]

fell.3SG.PAST a lot snow.PL.MASC

'A lot of snow fell/has fallen.'

5 Deal (2016) argues that the silent divider $\alpha_{n}$ may yield more than one quantized reading for a given NP. For example, the application to an NP with the substance noun for bread may give further readings such as the set of slices of bread or subkinds of bread in addition to the set of loaves of bread. Hence, Deal defines as follows:

(i) $\left[\left[\alpha_{n}\right]\right]^{g}=\lambda P \lambda x\left[\operatorname{AT}_{n}(P)(X)\right]$ where $\mathrm{AT}_{\mathrm{n}}=\mathrm{g}(\mathrm{n})=$ the $\mathrm{n}^{\text {th }}$ atomization function

Where there are more than one atomization function, the variable $n$ on the silent divider $\alpha_{\mathrm{n}}$ will select the right function for the given context. 


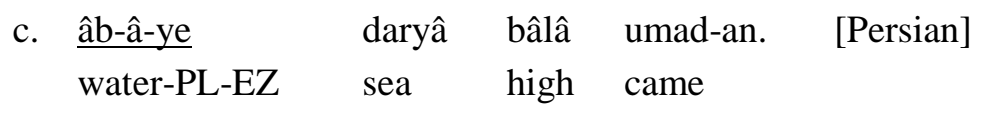
'The sea level rose.'

d. And he said unto them, Go. And they came out, and went into the swine: and behold, the whole herd rushed down the steep into the sea, and perished in the waters.

(Matthew 8: 32)

All the examples in (17) include pluralized substance nouns denoting either 'snow' or 'water', which are underlined. In spite of the plural morphology or syntax, they do not have counting or dividing interpretations. Rather, they have abundance readings in the sense of Corbett (2000), i.e., 'a lot of snow' or 'a lot of water'. In all these sentences, the exact counting of individuals is neither possible nor important. Instead, the pluralization simply delivers a large amount or volume of the substance. This means that the semantically substance readings are still tenable even with the plural-marking.

\subsection{Languages with No Count Nouns in Morpho-syntax}

In contrast with languages in which all nouns appear to behave like count morpho-syntactically, some languages appear to have only mass nouns. For example, in Dëne Suliné, a Northern Athapaskan language spoken in Northern Canada, nouns are neither numbermarked nor obligatorily followed by classifiers, occurring with a numeral (cf. Wilhelm 2008). In (18), the object noun k'ásba 'chicken' is not plural-marked even when it is preceded by the numeral solághe 'five'. 
16 The Interaction of Syntax and Semantics in Countability and Number Marking

(18) solághe k'ásba

five chicken

'five chickens'

The lack of number marking is a representative feature of mass nouns. The apparent masshood of the object nouns may not be sustained when it is compared with the morpho-syntactic structure of substance nouns. As shown in (19), the substance noun ejëretth'úé 'milk' is not allowed to occur with a numeral without the cooccurrence of classifier like trll.

$\begin{array}{lll}\text { (19) solághe ejëretth'úé } & \text { tilı } \quad \text { /\#ejëretth'úé } \\ \text { five } & \text { milk } & \text { container/milk } \\ \text { 'five cartons of milk' } & \end{array}$

The substance noun in (19) has a count reading only through the semantic application of unit, which amounts to a shifted reading from mass to count. In other words, the substance noun is mass, and it has a shifted reading to count, occurring with a container expression. The contrasted structure of (19) shows that the object noun in (18) is count in spite of the number-neutral morpho-syntax. Hence, Wilhelm (2008) argues that mass and count nouns are distinguished in Dëne in spite of the lack of number marking. The mandatory use of classifier shows whether given nouns are mass or count.

Mandarin is a language where number marking is not explicit in morpho-syntax. Hence, it has been a strong debate whether Mandarin has any count noun at all. In much literature, it was assumed that Mandarin consists of only mass nouns. However, Cheng \& Sybesma (1999) argue that object and substance nouns are morphosyntactically distinguished in a way that the modification marker de 
may follow only mass classifiers.
(20)
a. san bang (de) rou three CL-pound (de) meat 'three pounds of meat'
b. ba tou niu /*ba tou de niu eight CL-head cow/eight CL-head de cow 'eight cows'

$D e$ is not mandatory for any classifier but possible for mass classifiers like bang 'CL-pound'. However, de is not allowed to count classifiers like tou 'CL-head'. Therefore, Cheng \& Sybesma argue for the count-mass distinction in Mandarin despite the lack of number marking system.

The syntactic distinction between count and mass in Mandarin is further supported by the semantic evidence. Count adjectives like xiao 'small' may occur with the object noun shu 'book' but not with the substance noun rou 'meat'.
(21) Zhangsan xihuan xiao(-de) shu/*rou.
Zhangsan like small book/*meat
'Zhangsan likes small books/*meat.'

The restriction of count adjectives is quite robust to be noted crosslinguistically. Apparently, object and substance nouns are not distinguished strongly in Mandarin. However, the occurrence of count adjectives is restricted object nouns just like other languages. Therefore, it is concluded that Mandarin is also sensitive to the semantic feature of nouns. 


\section{Conclusions}

Basically, countability and number-marking reflect the denotations of NPs, and thus they are closely related with the denotations of NPs. However, information for countability (and possibly number) is mainly delivered by the syntax and morphology of NPs and other cooccurring phrases. Moreover, the morpho-syntactic information of NPs and co-occurring phrases may not be matched with the semantic properties of NPs. Hence, it needs to be considered how closely morpho-syntax and semantics are inter-related and in what way they are.

To pursue the issue, diverse linguistic data are carefully reviewed. As discussed in much literature, the semantic features of nouns affect the countability of nouns and their number marking. Which strategy is adopted for the marking of countability and number may vary. In spite of the diverse patterns of morpho-syntactic structures crosslinguistically, the semantic feature of animacy plays an important role in many languages. Furthermore, even in languages where countability and number distinction do not appear to be part of grammar, the semantic properties of nouns are still robust in the decision of the morpho-syntax of NPs and co-occurring phrases. Hence, object and substance nouns are distinguished in some ways and their denotations are reflected in the interpretations of sentences. Therefore, it is concluded that the semantics of NPs is deeply related with their morpho-syntax although specific patterns or structures are diverse. 


\section{References}

Bale, A. \& D. Barner. 2009. The Interpretation of Functional Heads:

Using Comparatives to Explore the Mass/Count Distinction. Journal of Semantics 26.3, 217-252.

Barner, D. \& J. Snedeker. 2005. Quantity Judgments and Individuation: Evidence that Mass Nouns Count. Cognition 97.1, 41-66.

Cheng, L. \& R. Sybesma. 1999. Bare and Not-so-bare Nouns and the Structure of NP. Linguistic Inquiry 30.4, 509-542.

Chierchia, G. 2010. Mass Nouns, Vagueness, and Semantic Variation. Synthese 174.1, 99-149.

Corbett, G. 1996. Minor Number and the Plurality Split. Rivista di linguistica 8.1, 101-122. . 2000. Number. Cambridge: CUP.

Deal, A. 2010. Topics in Nez Perce Verb. Ph.D. Dissertation, University of Massachusetts, Amherst. . 2016. Countability Distinctions and Semantic Variation. Manuscript, University of California Berkeley.

Evans, N. 1995. A-quantifiers and Scope in Mayali. In E. Bach et al. (eds.), Quantification in Natural Languages 207-270. Dordrecht: Kluwer.

Grimm, S. 2012. Individuation and Inverse Number Marking in Dagaare. In D. Massam (ed.), Count and Mass across Languages 75-98. Oxford: OUP.

Kwak, E. 2014. Cross-linguistic Evidence for Semantic Countability. Journal of Universal Language 15.2, 55-76.

Lima, S. 2014. The Grammar of Individuation and Counting. Ph.D. Dissertation, University of Massachusetts, Amherst.

Mathieu, E. 2012. On the Mass/Count Distinction in Ojibwe. In D. 
20 The Interaction of Syntax and Semantics in Countability and Number Marking

Massam (ed.), Count and Mass across Languages 172-198. Oxford: OUP.

Quine, V. 1960. Word and Object. Cambridge, MA: MIT Press.

Rice, K. 1989. A Grammar of Slave. Berlin: Mouton de Gruyter.

Smith-Stark, T. 1974. The Plurality Split. In M. La Galy, R. Fox \& A. Bruck (eds.), Papers from the 10th regional meeting 657-671. Cambridge: CUP.

Wilhelm, A. 2008. Bare Nouns and Number in Dëne Suliné. Natural Language Semantics 16.1, 39-68. 